\title{
STUDY OF NOZZLE INJECTOR PERFORMANCE USING CFD
}

\author{
Vimal Kumar Pathak ${ }^{1}$ and Sumit Gupta ${ }^{2}$ \\ ${ }^{1,2}$ Department of Mechanical Engineering, MNIT, Jaipur
}

\begin{abstract}
The aim of this paper is to study the performance of nozzle injector by changing its shape and fuels. Diesel injector orifice shape has an important role in defining the performance and emission characteristics of a diesel engine. It assist in adequate blending and atomisation of the fuel. Cavitation phenomena occurring inside the nozzle injector have an impact on the fluid flow dynamics which in turn affects the performance and emission characteristics of diesel engines. Also to restrict the emission caused by diesel engine many research is going on. In this paper, dimethyl ether (DME) is compared with diesel fuel by using CFD software. And to improve the performance of injector a comparison of cylindrical and conical orifice diesel injector has been done by using diesel and dimethyl ether. It has been observed that dimethyl ether with cylindrical orifice nozzle injector has more cavitating effects than the diesel fuel. Due to this, better fuel air mixing and atomisation of the fuel is achieved, that successively enhance the performance of the engine. And the emission of soot, SOx and NOx is greatly reduced by using dimethyl ether as the fuel due to its properties.
\end{abstract}

\section{KEYWORDS}

Diesel Injector, cylindrical orifice, conical orifice, Cavitation, DME, CFD.

\section{INTRODUCTION}

The performance of the diesel engine and its associated pollutant emission are greatly affected by the injection system and the properties of the fuel used. The injection method in diesel engine has vital impact on the fuel consumption, the combustion process and the emission [1]. Diesel engine performance and emission characteristics are largely governed by fuel atomisation, which is totally depend on the internal flow of nozzle injector. Fuel is injected inside the cylinder at a very high pressure to improve the atomisation and spray behaviour of the fuel. During the flow in injector,the pressure energy of the fuel gets converted into the kinetic energy, at the cost of pressure energy. Due to the significant fall in the pressure at the inlet of the nozzle injector, cavitation phenomena occur. As we move towards the exit of the nozzle the cavitation phenomena decreases [2]. Cavitation can improve spray breakup and enhances the performance of diesel injector systems. Also, improvement in the efficiency of the combustion process is one of the advantages. A well-designed fuel injector helps in ensuring quick and complete combustion. With the help of proper atomization of the fuel into very tiny droplets, the surface area of the droplets increases. Consequently, better mixing of air and fuel is achieved and hence, subsequent combustion [3]. Atomization is the process ofpressurizing the fuel across a mini aperture.

Though the power output of diesel engine is high but the main problem is the high level of NOx, soot and SOx emission. One of the biggest challenge in the expansion of diesel engine is the simultaneous reduction of NOx and smoke emission. So it becomes an essential thing to look for other option of fuel which can replace diesel. Some of the researchers reported about oxygenated fuels like dimethyl ether which can easily replace diesel as an alternative fuel. Cavitating

DOI : 10.14810/ijmech.2015.4312 
phenomenon is affected by the changes in the properties of fuel and developed a correlation between cavitation and fuel properties [2]. The thermo physical and transport properties of DME is different from diesel fuel, hence distinctive injection flow characteristics can be presumed.

The injector flow characteristics, have a significant impact on cavitation phenomena, injection rate of the fueland also on the turbulence at the nozzle exit.Inevitably, it affects the spray atomization and penetration and thus the performance.

This study gives a good comparison of two different shapes nozzle orifice and the flow characteristics of dimethyl ether and diesel fuel is investigated which is helpful in improving the diesel engine performance, fuel economy and restricting the pollutant emission of the diesel engine. For that purpose two orifices of nozzle injector have been taken with cylindrical and conical shape. These two nozzle orifices of different shape have been investigated by using commercial CFD (Computational Fluid Dynamics) software package.

\section{COMPUTATIONAL FLUID DYNAMICS (CFD) ANALYSIS}

Nowadays, Computational fluid dynamics (CFD) has become a progressively handy and robust tool for the numerical analysis involving transport processes. CFD provides understanding into flow design, which are laborious, costly or impossible to investigate using conventional techniques. It consists of simulation of multiphase flow, heat transfer, chemical reactions and particulate processes [4]. In CFD simulations, accuracy and reliability are the main factors upon which emphasise is given. It is broadly accepted that simulations performed by CFD are very susceptible to the various computational parameters that have to be set by the user. Consequently, CFD verification and validation studies are crucial, as well as comprehensive sensitivity studies that can deliver effective guidance in the selection of computational variables for future CFD studies [5]. In this paper, CFD analysis has been done to study the fluid flow analysis through nozzle injector. By using CFD tools it is possible to obtain unlimited level of details about the behaviour of the flow [6].

\section{Governing Equations}

The governing equations used by the CFD software package for this study are as follows: Conservation of Mass (Continuity Equation):

$$
\frac{D \rho}{D t}+\rho \nabla \cdot V_{x}=0
$$

Where,

$\frac{D \rho}{D t}=\frac{\partial \rho}{\partial t}+V_{x} \nabla \rho$ is the material derivative.

Conservation of Momentum (equation of motion):

$$
\rho \frac{D V_{x}}{D t}=-\nabla p-\nabla \cdot T+p . f
$$

Conservation of Energy (Temperature equation):

$$
\rho C_{p} \frac{D T}{D t}=\frac{D p}{d t}-\nabla \cdot q-\varphi
$$




\section{METHODOLOGICAL APPROACH}

Commercial software FLUENT 6.1.22 has been used for this simulation. The standard K- $€$ model of turbulence with segregated solver has been used for this study. The geometry of the nozzle injector has been generated as mesh file in GAMBIT 2.1.6. And then the mesh file is exported in FLUENT 6.1.22 where all the work has been done. The work was solved as 2D, axi-symmetric, unsteady. CFD simulations have been executed in unsteady reign, as needed by the cavitation model that is carry out in Fluent. The inlet and outlet boundary conditions are provided below:

The boundary conditions for the nozzle injector are as follows [7-8]:

1. Pressure Inlet -1400 bar

2. Pressure Outlet -60 bar

3. Temperature $-300 \mathrm{~K}$

4. Turbulence Kinetic Energy $-1 \mathrm{~m}^{2} / \mathrm{s}^{2}$

5. Turbulence Dissipation Rate $-1 \mathrm{~m}^{2} / \mathrm{s}^{3}$

The thermos-physical and transport properties of two fuels: Diesel and DME are listed in Table 1.

Table 1. Comparison of Properties of Fuel [9-10]:

\begin{tabular}{|c|c|c|}
\hline Fuel Properties & Dimethyl ether & Diesel \\
\hline General Formula & $\mathrm{CH} 3-\mathrm{O}-\mathrm{CH} 3$ & $\mathrm{CxHy}$ \\
\hline Molecular Weight, $\left(\mathrm{g} / \mathrm{cm}^{3}\right)$ & 46.07 & $190-220$ \\
\hline Density at $25^{\circ} \mathrm{C},\left(\mathrm{kg} / \mathrm{m}^{3}\right)$ & 667 & 840 \\
\hline Viscosity at $25^{\circ} \mathrm{C},(\mathrm{kgm} / \mathrm{s})$ & $6.67 \mathrm{E}-5$ & 0.00224 \\
\hline Surface Tension at $25^{\circ} \mathrm{C},(\mathrm{N} / \mathrm{m})$ & 0.012 & 0.0020 \\
\hline Vapour Pressure at $25^{\circ} \mathrm{C}(\mathrm{Pa})$ & 530000 & 1280 \\
\hline
\end{tabular}

\section{GEOMETRIC CONSTRUCTION AND GRID GENERATION}

The geometry specification is important in any kind of CFD simulation. It is fascinating to report the physical boundaries that contain the fluid as accurately as possible, particularly for engineering issues, wherever sometimes the impact of one or more synthetic, or design, objects are to be predicted. Any inaccurate specification of the boundary surfaces may give erroneous result. Geometric setup and grid generation used to take a month or longer to perform. Presently, the geometry setup and grid generation processes have been made effortless, since almost all the packages have CAD systems and automatic grid generation segments [11]. Figure 1 shows the schematic of nozzle injector showing the area on which the study is concentrated. The computational mesh (grid) file was made using the GAMBIT module of CFD as depicted in Figure 2

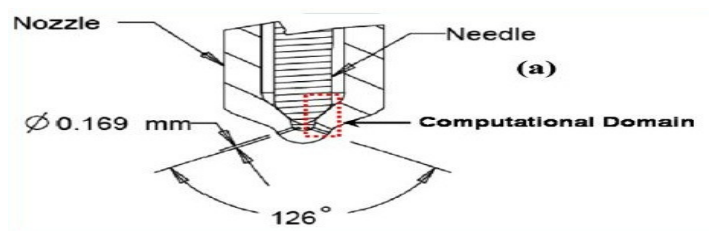

Figure1. Schematic of 6 hole mini-sac nozzle 


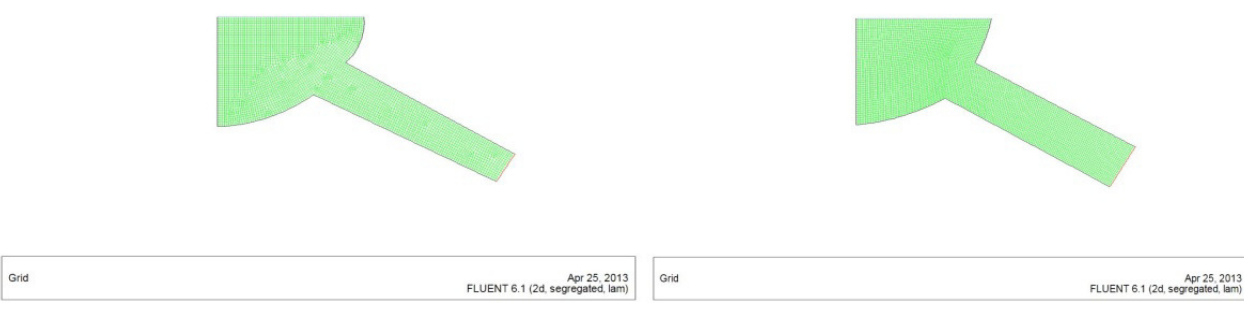

Figure2. Grid Displayof cylindrical and conical orifice nozzle injector

\section{RESULT AND DISCUSSION}

1. Figure 3 shows the pressure variation of diesel and DME fuel in cylindrical orifice nozzle injector. It clearly shows that there is sudden drop in pressure just at the inlet of the orifice for both fuels. But drop in pressure is more for DME fuel which clearly indicates the inception of cavitation phenomena. Because of cavitation phenomena only the vapour bubbles are produced at the inlet region along the walls of the nozzle orifice.
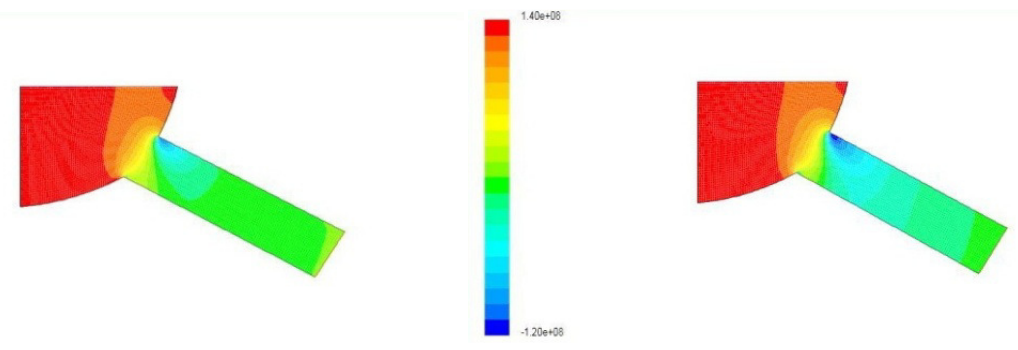

Figure3. Pressure Contour of Cylindrical orifice nozzle of diesel and DME fuel
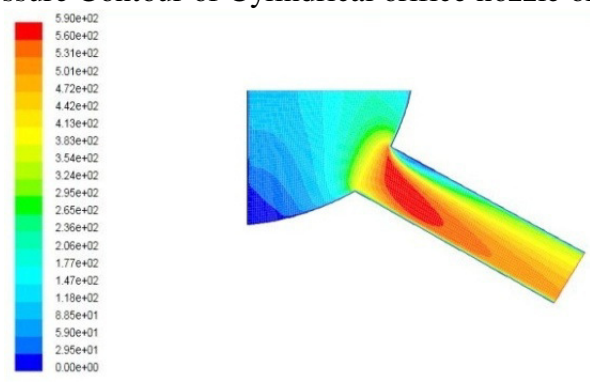

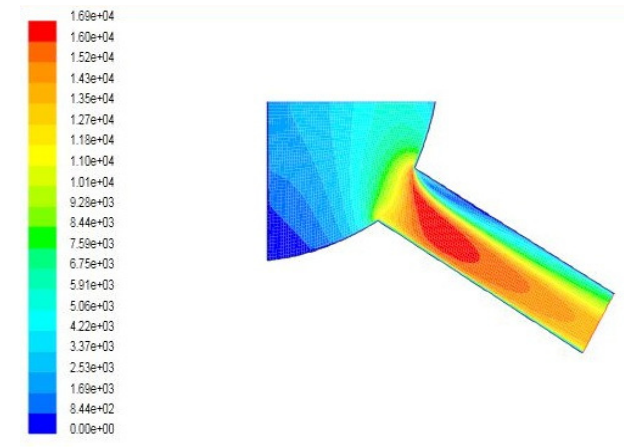

Figure 4. Velocity Contour of cylindrical orifice nozzle of diesel and DME fuel

Figure 4 shows the velocity contour for both the fuels indicating the variation in velocity throughout the orifice. Vapours formed near the inlet of the orifice reduce the available flow area and hence increasing the flow velocity. Above figure clearly shows there is an increase in the velocity of fluid at the inlet due to reduction of flow area. But the flow velocity for DME fuel is more than the diesel fuel due to decrease in pressure.
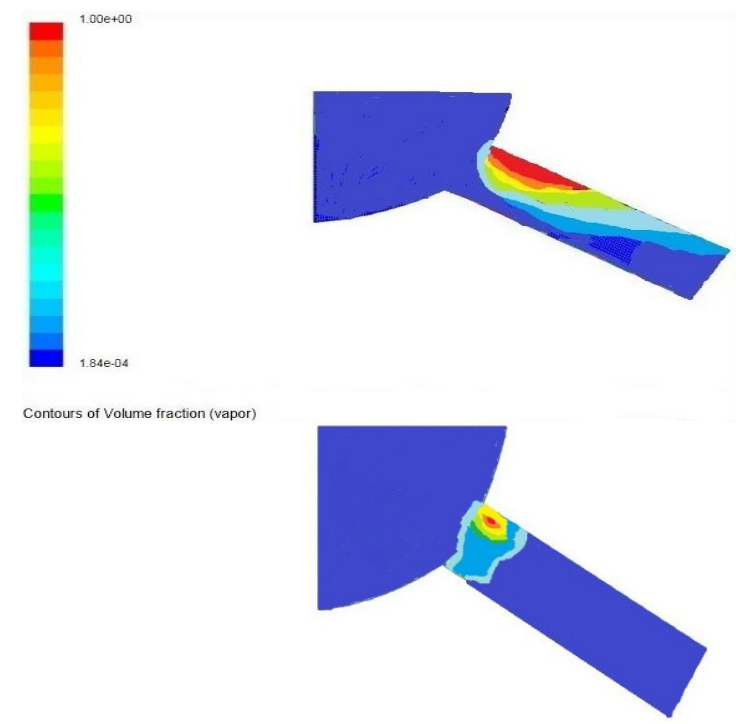

Figure 5. Volume fraction of cylindrical orifice having DME and diesel as fuel

Above figure explains the volume fraction of DME and diesel fuel. For DME fuel more vapour is formed at the inlet of the nozzle orifice which can be clearly seen in Figure 5. More volume of vapour at the inlet for DME fuel is due to the cavitation effect shown by it which is more than the diesel

fuel. 


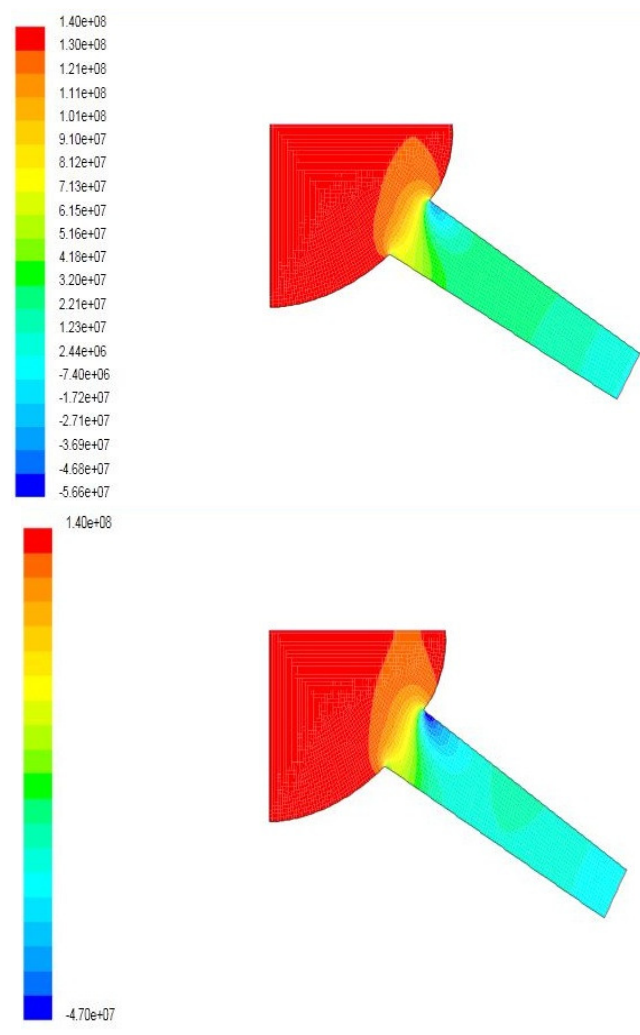

Figure 6. Pressure Contour of Conical orifice nozzle of diesel and DME fuel

Figure 6 shows the pressure contour of conical orifice for diesel and DME fuel. Also, the pressure drop for DME fuel is higher as compared with the diesel fuel as predicted which cause the initiation of the cavitation phenomena. But the decrease in pressure is not less than the cylindrical orifice nozzle injector using DME fuel.
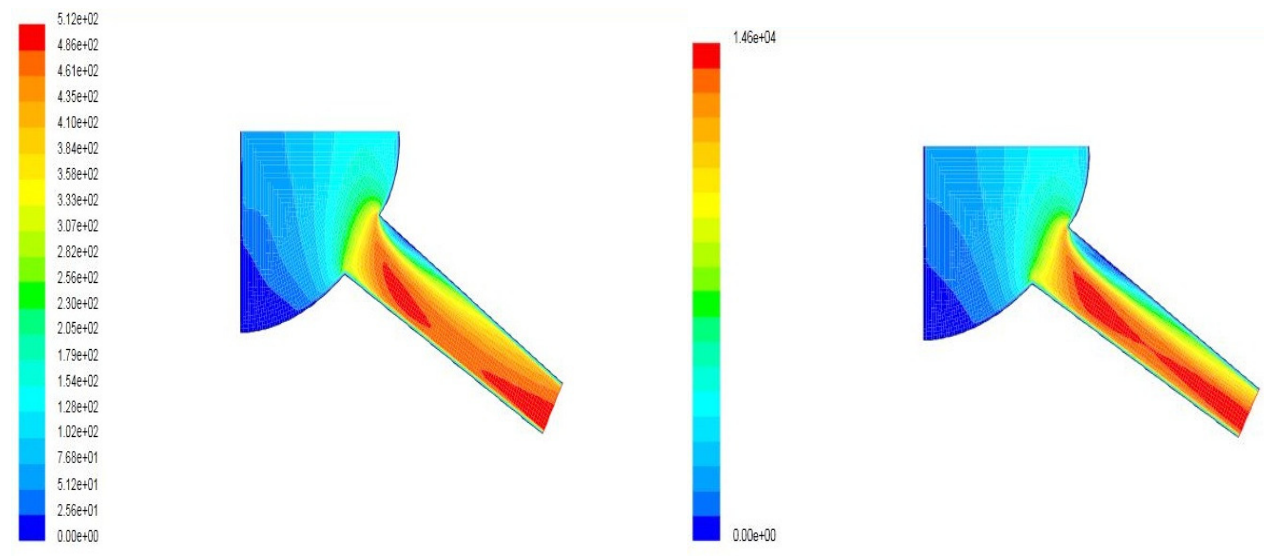

Figure 7. Velocity Contour(Conical orifice) of diesel and DME fuel

Due to sudden fall in pressure, there is an increase in the velocity of the nozzle orifice. But again the DME fuel has more velocity than the diesel fuel due to reduction in flow area because of the 
presence of vapor bubble present at the inlet of orifice due to the cavitation phenomena.Now the comparison of cylindrical and conical nozzle orifice having DME and diesel as fuel has been done with the help of graphs between the position and the pressure as shown in figure 8 .

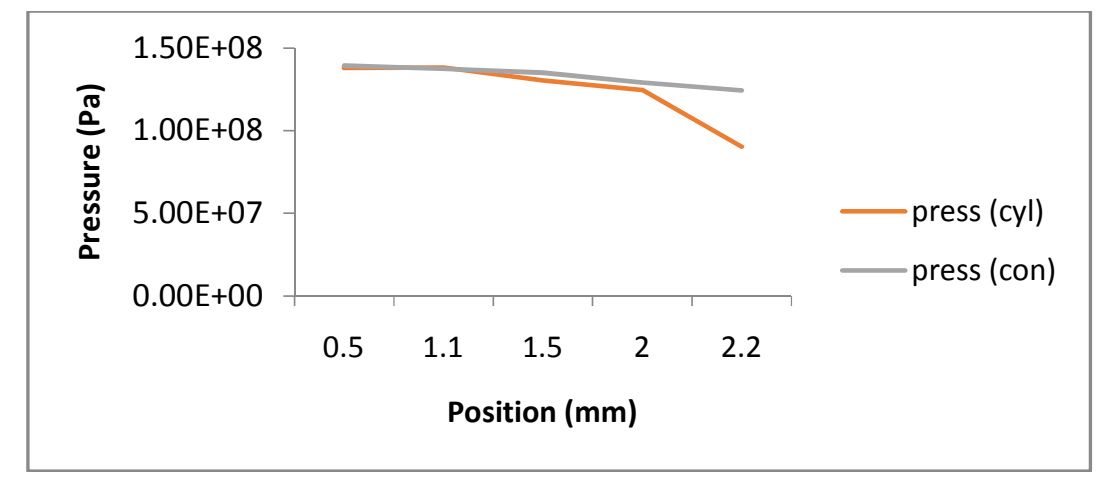

Figure 8.Position and pressure for DME fuel for cylindrical and conical nozzle injector

Variation of pressure for the different positions in the nozzle injector is shown in the figure.8. This figure clearly shows the pressure drop for cylindrical orifice nozzle is more than the conical orifice nozzle which helps in inception of cavitation when using DME fuel. Figure 9 shows the variation of velocity with the position which clearly indicates that cylindrical orifice nozzle injector has more velocity than the conical one. This is basically due to the reduction of flow area due to the presence of vapor bubbles produced due to cavitation phenomena.

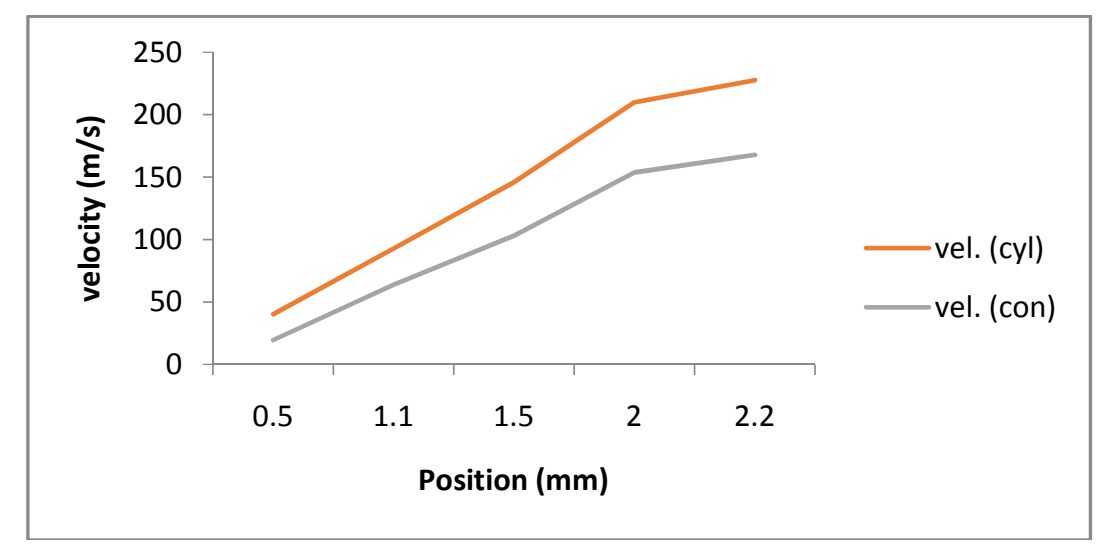

Figure 9. Variation of velocity with position for DME fuel for cylindrical and conical nozzle

\section{CONCLUSION}

The main aim of this paper is to study the performance of nozzle injector under different fuels and distinctive shapes of orifice. This paper gives following conclusion:

1.Dimethyl ether (DME) fuel shows more cavitating characteristics than the diesel fuel because of the lesser density and viscosity.

2.Cylindrical orifice nozzle injector has more cavitation than the conical orifice nozzle injector. 3.Cylindrical orifice nozzle injector is better than the conical orifice nozzle injector because the increase in velocity cause the mass flow rate to reduce. 
4.Due to which better mixing of air and fuel is possible and hence proper atomization can be achieved which can cause an increase in diesel engine performance by reducing the time for ignition delay. Also, DME fuel will reduce the pollutant emission up to certain limit.

\section{REFERENCES}

[1] F. Echouchene, H. Belmabrouk, L Le Penvan, M. Buffar (2009), “Analysis of cavitation in Diesel Injectors.” International renewable energy congress, pp. 91-99.

[2] Thulasi Vijay Kumar, RajagopalThundilKaruppa Raj, and KasiananthamNanthagopal (2011), "Effect of the injection pressure on the internal flow characteristics for diethyl and dimethyl ether and diesel fuel injectors."Center for Excellence in Automotive Technology,Vol. 15(4), pp 1123-1130.

[3] M.L.S Deva Kumar, S.Drakshayani, K.Vijaya Kumar Reddy (2012), "Effect of Fuel Injection Pressure on Performance of Single Cylinder Diesel Engine at Different Intake Manifold Inclinations".'International Journal of Engineering and Innovative Technology, Vol. 2(4), pp 20-28.

[4] E. Kougoulos, A. G. Jones and M. Wood-Kaczmar (2005),’CFD Modelling Of mixing and heat transfer in batch cooling crystallisers. Aiding the Development of a Hybrid Predictive Compartmental Model", Chemical Engineering Research and Design, Vol. 83(A1), pp 30-39.

[5] R. Ramponi, B. Blocken, "CFD simulation of cross-ventilation flow for different isolated building configurations: Validation with wind tunnel measurements and analysis of physical and numerical diffusion effects", Journal of Wind Engineering and Industrial Aerodynamics, Volumes 104-106, May-July 2012, Pages 408-41.

[6] Raul Payri, S. Molina, F. J. Salvador, J. Gimeno (2004), “A study of the relation between Nozzle geometry Internal flow and Spray Characteristics in Diesel Fuel Injection Systems", KSME International Journal, Vol. 18(7), pp. 1222 - 1235.

[7] Hyun Kyu Suh a, Chang Sik Lee (2008),'Effect of cavitation in nozzle orifice on the diesel fuel atomization characteristics, International Journal of Heat and Fluid Flow”, Vol. 29, pp 1001-1009.

[8] R. Payri, F.J. Salvador, J. Gimeno, J. De la Morena (2011),"Influence of injector technology on injection and combustion development - Part 1: Hydraulic characterization", Applied Energy, Vol. 88, pp 1068-1074.

[9] H. W. Wang, L.B. Zhou, D. M. Ziang, Z. H. Huang (2000), "Study on the performance and emission of a compression ignition engine fuelled with dimethyl ether," Proceedings of the institution of mechanical engineers Part D Journal of Automobile Engineering, Vol. 214, pp 101-106.

[10] A Kowalewicz, MWojtyniak (2004),"New alternative fuels for I.C. Engines- A review," Journal of KONES International Combustion Engines, Vol. 45,pp 358-368.

[11] MitevRanjan, Karan Kumar, Subrata Kr. Ghosh," Mine ventilation in a board and pillar mines using CFD". International Journal of Emerging Technology and Advanced Engineering, Vol. 3(3), ICERTSD 2013, pp 389-393. 